\title{
Osteoporosis, an underestimated epidemic?
}

\author{
Tim C Krappel ${ }^{1 *}$ and Ferdinand A Krappel ${ }^{2}$ \\ ${ }^{1}$ School of Management, Economics, Law, Social Sciences and International Affairs, University of St. Gallen, Brig, Switzerland \\ ${ }^{2}$ Department of Orthopaedics, Spitalzentrum Oberwallis, Brig, Switzerland
}

\begin{abstract}
Purpose: Osteoporosis is a widespread disease in aging Western societies, and powerful diagnostic and therapeutic tools have been developed in the past decade. However, in clinical practice we notice that a fair number of at-risk patients remain undiagnosed and/or untreated, with potentially avoidable individual suffering and high costs for society. Since diagnosis can be delayed by lack of both physician and patient awareness, we evaluated the level of knowledge about osteoporosis among older patients with orthopaedic disorders.
\end{abstract}

Methods: A semi-structured questionnaire was handed out, over a period of one month, to outpatients $\geq 50$ years old seen at a local Swiss cantonal hospital. Patients where asked about osteoporosis, perceptions of own disability, and diagnostic tests. Descriptive statistics were used to report the data.

Results: Of the 197 patients included in the study, the majority had heard about osteoporosis, but only 20\% could reasonably describe the disease. Regarding diagnosis, $44 \%$ of the women and $5 \%$ of the men claimed they had done a bone density scan, even though only $30 \%$ of the women and $3 \%$ of the men appeared to have had one. Osteoporosis was diagnosed in $47 \%$ of the patients evaluated. Vitamin D levels were measured in only $22 \%$ of the patients, a total of $30 \%$ reported loss of height, and $22 \%$ reported frequent falls.

Conclusion: Despite ours being a society with readily available medical information, awareness of osteoporosis in our region was low. Whether this is a local phenomenon will need to be confirmed in a nationwide study.

\section{Introduction}

Osteoporosis constitutes a key public health issue in aging western societies, since it leads to significant disability and decreased quality of life for the individuals affected, and higher costs for society as a whole. It is estimated that, with the aging of the population, the number of osteoporotic fractures will triple in North America in the near future. When the disease is left untreated, over $50 \%$ of postmenopausal Caucasian women have an osteoporotic-related fracture, with increased morbidity, mortality, and disability [1,2].

One can expect similar numbers in Switzerland, although no such statistics are available. A large amount of information is readily available to the public online, as well as through mass and social media and self-help groups, and powerful tools have been developed for early diagnosis, prevention, and management. Despite these advancements, we often notice in our daily clinical practice that a fair proportion of patients remain undiagnosed and are, therefore, potentially also left untreated, which results in avoidable suffering for individuals and in a significant burden for society. This situation is particularly worrisome since preventing the progression of osteoporosis seems to be more relevant and effective than simply managing its complications [3]. In light of recent evidence, disease awareness gains particular importance where preventive care is based on evidence, whilst management of complications is not. To assess the level of knowledge about osteoporosis, we conducted a survey to determine what patients in the target age group $\geq 50$ years old know about the disease and what they think it is. Further to those questions, the patients were asked about their perceptions of their own physical ability and whether they had undergone any form of diagnostics tests such as dual energy x-ray absorptiometry (DEXA) scans or vitamin D measurements.

\section{Methods}

For one month, all patients aged $\geq 50$ years who were seen at the outpatient orthopaedics department of a cantonal hospital in Switzerland were asked to fill out a short questionnaire (Supp. Information). Patients were asked about their age and sex, whether they had ever heard about osteoporosis, and what they thought it was. They were also asked whether they had lost height, if they had frequent falls, and if they had a DEXA scan or a vitamin D measurement and a diagnosis of osteoporosis. Women were also asked about their menopausal status. Descriptive statistics were used to present the data.

\section{Results}

\section{Demographic data}

A total of 197 outpatients (104 women and 93 men) consented to participate in the study and were available for further evaluation. The average age was approximately 66 years, with the female patients being slightly older than the male ones (67.0 vs. 64.5 years, respectively). There were two peaks in age distribution, one at 53 to 58 and the other at 71 to 76 years of age. The majority of the older participants were women (Figure 1).

${ }^{*}$ Correspondence to: Tim Christopher Krappel, School of Management, Economics, Law, Social Sciences and International Affairs, University of St. Gallen, Bachtrasse 110, CH 3900 Brig, Switzerland, E-mail: krappeltim@gmail.com

Key words: osteoporosis, diagnosis, epidemiology, patient awareness

Received: October 12, 2020; Accepted: October 27, 2020; Published: November 06,2020 


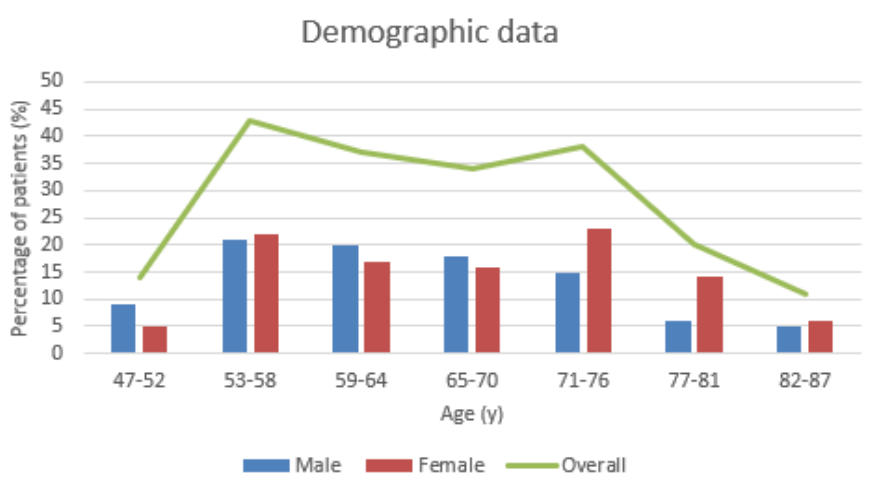

Figure 1. Study population by sex and age

Regarding menopause status, two 60-year old women reported still having their menstrual periods at the time of the survey, and 22 said they did not know when they had stopped. For the remaining 80, the average time since menopause was 17.1 years (range: $1-40$ ).

\section{Awareness of osteoporosis}

The questions "Have you ever heard about osteoporosis?" and "Can you describe what it means?" were evaluated together, since having heard the word 'osteoporosis' does not necessarily mean grasping the concept. The answers to the open question to describe the disease were categorized into two groups: 1) patients provided answers such as 'bone loss' or 'weak bones' (i.e. they had an idea of the disease, but knew nothing about its treatment and diagnosis); and 2) patients were able to give some meaningful explanation of the diagnosis and also provided some information about diagnostic procedures/treatment or, even more important, stated that the disease can actually be treated. We considered answers in group 1) as "negative" (i.e. "useless knowledge"), and in group 2) as a "passing the test".

Our survey revealed that a total of 111 out of 197 patients (56\%) had heard about osteoporosis; of these, $39(20 \%)$ provided a meaningful explanation of the disease, and $86(44 \%)$ said that they had not heard about it. Evaluating the two questions in combination showed that only 11 (12\%) of men and 28 (27\%) of women had a meaningful idea of osteoporosis (Figure 2a).

\section{Perception of health status}

The perception of oneself and own fitness level as well as mobility is an important component of quality of life. To obtain a general idea of the patients' self-perceptions regarding their health status and physical ability, we asked them about their height.

Overall, 58 (29\%) of the patients said they had become shorter, 92 (47\%) reported no change in height, and 47 (24\%) did not know if their height had changed. A total of $26 \%$ of the men answered yes to height change, $65 \%$ answered no, and $9 \%$ did not know, whereas $43 \%$ of the women answered yes, $32 \%$ no, and $24 \%$ did not know (Figure $2 \mathrm{~b}$ ). For the 16 patients with a diagnosis of osteoporosis, $9(56 \%)$ reported losing height, 5 (31\%) did not see a change, and $2(13 \%)$ said they did not know.

\section{Falls and insecurity when walking}

Falls are a significant cause of fractures in the elderly. A fall without any other causing factors and insecurity when walking was reported by $44(22 \%)$ of the patients, with $150(74 \%)$ answering no, and $3(4 \%)$ saying they did not know.

\section{Diagnosis of Osteoporosis}

Patients were also asked about the diagnosis of osteoporosis, namely whether they had a vitamin D measurement or a DEXA scan, and if they had actually received a diagnosis of osteoporosis (Figure 2c).

Of all the participants, 126 (64\%) did not have a DEXA scan, $21(10 \%)$ said they did not know, and only $50(25 \%)$ had one exam performed. Of these 50 patients, $16(32 \%)$ received a diagnosis of osteoporosis and 18 (36\%) had no osteoporosis. Much to our surprise,

\section{Have you ever heard about osteoporosis?}



" No $=$ Yes-passed the test $\|$ Yes-failed the test

(A)

\section{Have you become shorter?}

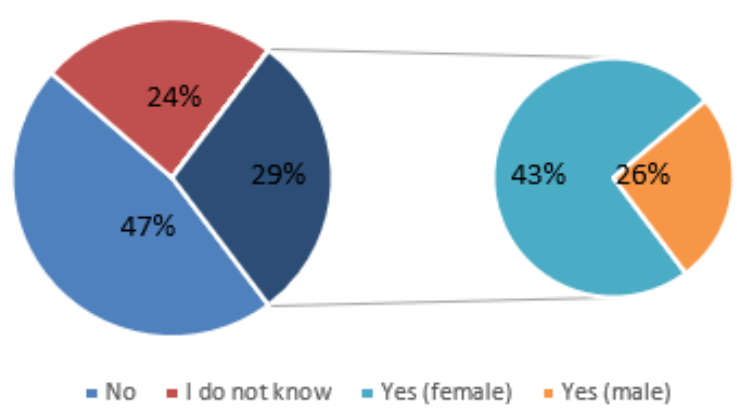

(B)

\section{Have you had a DEXA scan?}



(C)

Figure 2. Proportion of patients who were aware/not aware of osteoporosis (a) and patient distribution for self-perception of health status (b) and diagnosis of osteoporosis (c) 
$16(32 \%)$ of the patients tested did not recall the result of the scan and did not know whether they had osteoporosis or not. Of those 50 patients reporting having had a DEXA scan, $5(10 \%)$ were men and 45 (90\%) were women, correctly indicating the overrepresentation of osteoporosis seen in women.

Vitamin D measurements were performed in 45 (22\%) of all the participants (12\% of men and 32\% of women), with 107 (54\%) answering no and 45 (22\%) saying they did not know whether they had their vitamin D levels measured. When asked about the diagnosis of osteoporosis, 22 (11\%) replied that they had received a diagnosis, 94 (48\%) claimed that they did not have the disease, and 81 (41\%) said that they did not know whether they had it or not.

Only 34 (17\%) patients in the whole cohort provided their answers based on a DEXA scan, so 16 (8\%) overall had osteoporosis and $18(9 \%)$ did not. The bone status of the other $163(83 \%)$ patients is unclear.

\section{Discussion}

Osteoporosis is a common chronic disease in aging populations with increasing incidence worldwide [4]. Since the "baby boomers" in Switzerland are now over 55 years old, issues related to bone health and chronic conditions have not only become medical issues, but also a socio-economic burden [5]. Despite the increase in its prevalence, osteoporosis is widely recognized as a preventable and treatable disease, and appropriate detection and management, including lifestyle modifications, may minimize the pressure on public health resources. Although the current clinical guidelines recommend cessation of tobacco use, avoidance of excessive alcohol intake, participation in regular exercise activities, and an adequate intake of calcium and vitamin D for maintaining bone health [6], several studies have shown that patients with osteoporosis do not follow the recommendations after receiving a diagnosis of the disease [7].

In our daily practice we may even observe that many patients in the relevant age group do not have a clear idea of what osteoporosis is, despite the fact that one can read about it almost everywhere and the availability of self-help groups and awareness campaigns by public health entities and health insurance companies. This observation prompted us to conduct this study. Unfortunately, the results seem to confirm our initial perceptions: only a small minority, about one-fifth, of the patients participating in the survey had a meaningful idea of what osteoporosis was and what to do about it. A meaningful explanation represents educated patients with information that helps them become responsible for their own health. Moreover, approximately one-fourth of the patients claimed to have done a DEXA scan, and of those less than one-tenth said they had received a diagnosis of osteoporosis. Finally, approximately one-tenth of the patients said that their DEXA scans were normal and, astonishingly, an almost equal proportion said they did not know the result.

Other studies have shown similar low awareness levels. Data obtained from 2,870 Korean women aged $\geq 50$ years who had received a DEXA scan revealed that osteoporosis was reported in $39.1 \%$. Among those with osteoporosis, only $37.5 \%$ were aware of their diagnosis and $23.5 \%$ received pharmacological treatment [8]. In another study, osteoporosis awareness was determined by the simple question: "Have you been diagnosed with osteoporosis?"; if the patients answered yes, they were included in the osteoporosis awareness group [9]. Our results suggest that this may be misleading, since more patients confirmed they had heard about osteoporosis but did not have a useful knowledge of it. Even among those undergoing a DEXA exam, almost one-third did not know what the result of the test was and its meaning.
Falls are known to be a significant cause of morbidity and mortality in aging populations. A fall without any other causative factors and insecurity when walking was reported by approximately one-fifth of the patients, with three-fourths reporting no falls. In addition, almost one-third of the patients said they had become shorter, with almost half reporting no changes in height. In the absence of deformity, losing height is a classical clinical sign of osteoporosis; the stooped over posture makes people more prone to falls and insecure when walking, which are also positively correlated with vitamin D deficiency. Moreover, when people are afraid of falling, they exercise less and become less active, which in turn increases the risk of osteoporosis. In our survey we did not ask specifically about physical activity, which of course plays an important role in the prevention of falls, or about deformity, which may be a concurrent reason for the loss of height. Considering these shortcomings and the small sample of this study our results ought not to be over-interpreted, and no final conclusions can be drawn for the entire population of the country.

There seems to be overall agreement in the literature that calcium and vitamin $\mathrm{D}$ are essential for reducing fracture risk and improving bone density and that bisphosphonate therapy is mostly effective [1014]. Our results show that a minority of the surveyed patients had their vitamin D levels measured, only about one-fifth (approximately oneeighth of male and one-third of female patients). In line with these numbers, about one-tenth reported having a diagnosis of osteoporosis, with almost half claiming that they did not have the condition, and the remainder saying that they did not know whether they have it or not. Surprisingly, the question about menopause also generated confusing results: two women aged 60 years answered that they still had their periods, with 22 saying they did not know when they had stopped, but the average number of years since menopause was approximately 17 years.

Looking at our results, one may simply conclude that the public does not take an interest in the disease, but this is a small sample study within one Swiss canton only. The results may, therefore, be influenced by regional and socioeconomic factors; the canton analysed is a more rural area, where there is on average a greater interest in the practice of outdoor sports, so it comes as no surprise that osteoporosis is not on the list of concerns of the population. These findings would have to be corroborated in a much larger study involving multiple centres nationwide. Nevertheless, our results seem to convey the important message that the interest of the lay public in this disease is weak.

Despite the obvious limitations of this study, our results indicate a lack of awareness about the disease. Corrective measures such as providing adequate information on osteoporosis will be critical in guiding patients towards better bone health behavior [13]. In fact, a Korean study demonstrated that consultation with a doctor following a diagnosis of osteoporosis and osteopenia was the only factor associated with receiving treatment [14]. In addition, a systematic review pointed out to the need to deliver such knowledge over time [15], whilst a consultation with a doctor after being diagnosed with osteoporosis may be an effective strategy to increase awareness and therapy [16].

In summary, despite significant efforts from health authorities and institutions, the low rate of osteoporosis awareness in our study population suggests a need for better patient education, including comprehensive and easy-to-understand education materials, so that patients can take a proactive role in their own care and work to prevent or minimise the complications of osteoporosis. 


\section{Funding}

Not applicable.

\section{Conflicts of interest/Competing interests}

The authors declare that they have no conflicts of interest.

\section{Ethics approvals}

The study was approved by the institutional ethics committee and was performed in accordance with the ethical standards laid down in the 1964 Declaration of Helsinki.

\section{Consent to participate}

Informed consent was obtained from all individual participants included in the study.

\section{References}

1. Varacallo MA, Fox EJ (2014) Osteoporosis and its complications. Med Clin North Am 98: 817-831. [Crossref]

2. Kanis JA, Johansson H, Harvey NC, McCloskey EV (2018) A brief history of FRAX. Arch Osteoporos 13: 118. [Crossref]

3. Ebeling PR, Akesson K, Bauer DC, Buchbinder R, Eastell R, et al. (2019) The efficacy and safety of vertebral augmentation: a second ASBMR Task Force report. J Bone Min Res 34: 3-21. [Crossref]

4. Reginster JY, Burlet N (2006) Osteoporosis: A still increasing prevalence. Bone 38: S4-S9. [Crossref]

5. Choi HJ, Shin CS, Ha YC, Jang S, Jang S, et al. (2012) Burden of osteoporosis in adults in Korea: a national health insurance database study. J Bone Miner Metab 30: 54-58. [Crossref]
6. Svedbom A, Ivergård M, Hernlund E, Rizzoli R, Kanis JA (2014) Epidemiology and economic burden of osteoporosis in Switzerland. Arch Osteoporos 9: 187. [Crossref]

7. Greenspan SL, Bilezikian JP, Watts NB, Berry CA, Mencia WA, et al. (2013) A clinician performance initiative to improve quality of care for patients with osteoporosis. $J$ Women's Health 22: 853-861. [Crossref]

8. Patel A, Coates PS, Nelson JB, Trump DL, Resnick NM, et al. (2003) Does bone mineral density and knowledge influence health-related behaviours of elderly men at risk for osteoporosis? J Clin Densitom 6: 323-329.

9. Kim KH, Lee K, Ko YJ, Kim SJ, Oh SI, et al. (2012) Prevalence, awareness, and treatment of osteoporosis among Korean women: The Fourth Korea National Health and Nutrition Examination Survey. Bone 50: 1039-1047. [Crossref]

10. Shin H-Y, Kang HC, Lee K, Park SM (2014) Association between the awareness of osteoporosis and the quality of care for bone health among Korean women with osteoporosis. BMC Musculoskeletal Disorders 15: 334. [Crossref]

11. Boonen S, Rizzoli R, Meunier PJ, Stone M, Nuki G, et al. (2004) The need for clinical guidance in the use of calcium and vitamin $\mathrm{D}$ in the management of osteoporosis: a consensus report. Osteoporos Int 15: 511-519. [Crossref]

12. Mithal A, Wahl DA, Bonjour JP, Burckhardt P, Dawson-Hughes B, et al. (2009) Global vitamin D status and determinants of hypovitaminosis D. Osteoporos Int 20: 18071820. [Crossref]

13. Bischoff-Ferrari HA, Dawson-Hughes B, Orav EJ, Staehelin HB, Meyer OW, et al (2016) Monthly high-dose vitamin D treatment for the prevention of functional decline: a randomized clinical trial. JAMA Intern Med 176: 175-183. [Crossref]

14. Bolland MJ, Grey A, Avenell A (2018) Effects of vitamin D supplementation on musculoskeletal health: a systematic review, meta-analysis, and trial sequential analysis. The Lancet Diabetes\& Endocrinology 6: 847-858.

15. Ryan P, Schlidt A, Ryan C (2013) The impact of osteoporosis prevention programs on calcium intake: a systematic review. Osteoporos Int 24: 1791-1801. [Crossref]

16. Jeon YJ, Kim JW, Park JS (2014) Factors associated with the treatment of osteoporosis in Korean postmenopausal women. Women Health 54: 48-60. [Crossref]

Copyright: $@ 2020$ Krappel TC. This is an open-access article distributed under the terms of the Creative Commons Attribution License, which permits unrestricted use, distribution, and reproduction in any medium, provided the original author and source are credited. 